\title{
The Isolation and Characterization of Three Types of Vitamin B6 Auxotrophs of Escherichia coli K12
}

\author{
By ROBERT C. HOCKNEY* AND THOMAS A. SCOTT \\ Department of Biochemisty, University of Leeds, \\ 9 Hyde Terrace, Leeds LS2 $9 L S$ \\ (Received 30 May 1978; revised 16 August 1978)
}

\begin{abstract}
Approximately 500 vitamin B6 auxotrophs were isolated from 18 independent cultures of Escherichia coli strain CR63. None grew in minimal medium supplemented with 2'-hydroxypyridoxine. Eighteen auxotrophs which had arisen independently were further characterized. All of them were defective in vitamin B6 synthesis rather than in an aminotransferase involved in vitamin B6 utilization. Two different phenotypes were recognized: 'Oxidase' mutants which grew only when supplied with pyridoxal or pyridoxal 5 '-phosphate and 'Pre Pn' mutants which would also grow with pyridoxine or pyridoxine phosphate. 'Oxidase' mutants were confined to a single linkage group, but data from interrupted mating experiments established that 'Pre Pn' mutants fall into two linkage groups which are possibly identical to $p d x A$ and $p d x B$. All mutations in the $p d x A$ region were allelic rather than located in two closely linked genes.
\end{abstract}

\section{INTRODUCTION}

The biochemistry and genetics of vitamin B6 biosynthesis are only partially understood. A number of vitamin B6 auxotrophs of Escherichia coli B have been isolated and nine different genotypes assigned to them on the basis of cross-feeding tests (Dempsey \& Pachler, 1966; Dempsey, 1969a). Subsequently the mutations in these strains were divided into five distinct chromosomal linkage groups. The location of linkage group II, comprising $p d x E$ and $p d x G$ mutations, near pyr $A$ at 1 min (Dempsey, $1969 a, b$ ) suggested that this group might be analogous to the single $p d x A$ mapped in $E$. coli $\mathrm{K} 12$ (Taylor \& Trotter, 1967). Mutations assigned to $p d x A$ in $E$. coli K12 might therefore be located in two closely linked genes.

The understanding of vitamin B6 biosynthesis has been hindered by the often mistaken classification of ' $\mathrm{Km}$ ' mutants as vitamin B6 auxotrophs. These mutants can synthesize vitamin B6 normally, but synthesize an aminotransferase with reduced affinity for its cofactor (Guirard et al., 1971; Bukhari \& Taylor, 1971; Henderson \& Snell, 1971); they therefore require either vitamin B6 or an amino acid for growth.

The isolation and characterization of vitamin B6 auxotrophs of $E$. coli $\mathrm{K} 12$ reported here was performed to develop a rapid screen against ' $\mathrm{Km}$ ' mutants and to determine whether all mutations in $p d x A$ are allelic. The availability of a large number of vitamin B6 auxotrophs also allowed an investigation of the significance of $2^{\prime}$-hydroxypyridoxine in vitamin B6 biosynthesis. This compound is converted to pyridoxine and pyridoxal 5 '-phosphate in Kloeckera apiculata (Scott \& Picton, 1976) and we have now examined whether it can satisfy the growth requirement of vitamin B6 auxotrophs of E. coli.

* Present address: Research Laboratories, Bass Production Ltd, High Street, Burton-on-Trent DE14 1JZ. 


\section{METHODS}

Bacterial strains, The characteristics and sources of all Escherichia coli $\mathrm{K} 12$ strains are given in Table 1. Media. The glucose/salts (G/S) medium of Davis \& Mingioli (1950) was supplemented as required with pyridoxal $\left(120 \mathrm{ng} \mathrm{ml}^{-1}\right)$, L-amino acids $\left(40 \mu \mathrm{g} \mathrm{ml}^{-1}\right)$, DL-amino acids $\left(80 \mu \mathrm{g} \mathrm{ml}^{-1}\right)$, thiamin $\left(1 \mu \mathrm{g} \mathrm{ml}^{-1}\right)$ and adenine $\left(50 \mu \mathrm{g} \mathrm{ml}^{-1}\right)$. For transduction and cross-feeding tests, minimal medium $\mathrm{E}$ of Vogel \& Bonner (1956) and $\beta$-glycerophosphate medium of Torriani \& Rothman (1961), respectively, were used. Medium E was enriched with $0.2 \%(\mathrm{v} / \mathrm{v}) \mathrm{L}$-broth (Lennox, 1955). Glucose $(0 \cdot 2 \%, \mathrm{v} / \mathrm{v})$ was the principal carbon source in all defined media. L-broth was used as complete medium. Where appropriate, all media were solidified with $1.5 \%(\mathrm{w} / \mathrm{v})$ agar (Lab M), except in the preparation of lysates in which the concentrations of agar in the top and bottom layers were 0.6 and $1.0 \%$, respectively.

Isolation of vitamin B6 auxotrophs. All vitamin B6 auxotrophs were selected from mutagen-treated cultures of strain CR63, using the penicillin enrichment procedure of Dempsey \& Pachler (1966). Mutagens were employed as follows: ultraviolet (u.v.) radiation, $5 \mathrm{ml}$ cultures $\left(2 \times 10^{8}\right.$ bacteria $\left.\mathrm{ml}^{-1}\right)$ were irradiated under predetermined conditions in order to achieve $99.99 \%$ kill; ethyl methanesulphonate (EMS), $0.1 \mathrm{ml}$ cultures $\left(2 \times 10^{8}\right.$ bacteria $\left.\mathrm{ml}^{-1}\right)$ were diluted with $1 \mathrm{ml}$ of $0.1 \mathrm{M}$-EMS in $0.5 \mathrm{M}$-potassium phosphate $\mathrm{pH} 7.5$ and incubated at $35^{\circ} \mathrm{C}$ for $15 \mathrm{~min}$; nitrous acid, $1 \mathrm{ml}$ cultures $\left(2 \times 10^{8}\right.$ bacteria $\left.\mathrm{ml}^{-1}\right)$ were diluted in $2 \mathrm{ml}$ of freshly prepared $0.05 \mathrm{M}$-sodium nitrite $/ 3 \mathrm{M}$-sodium acetate $\mathrm{pH} 4.5(1: 1, \mathrm{v} / \mathrm{v})$ and incubated at $37^{\circ} \mathrm{C}$ for $7.5 \mathrm{~min}$; $N$-methyl- $N^{\prime}$-nitro- $N$-nitrosoguanidine (NTG), this was used as described by Adelberg $e$ t al. (1965). Cultures treated with EMS were diluted $1 / 100$ in L-broth and incubated at $37{ }^{\circ} \mathrm{C}$ until fully grown. All other cultures were diluted $1 / 100$ in $\mathrm{G} / \mathrm{S}$ plus pyridoxal and similarly incubated.

Cross-feeding tests. A modification of the method of Dempsey \& Pachler (1966) was used: about $10^{9}$ bacteria of each auxotroph were spotted on to $12 \mathrm{ml}$ glycerophosphate agar seeded with one of the other auxotrophs at $10^{7}$ bacteria $\mathrm{ml}^{-1}$. Cross-feeding was indicated by a halo of growth around and under the feeding clone after $2 \mathrm{~d}$ at $37^{\circ} \mathrm{C}$. All tests were repeated four times.

Transduction. The method of Guest (1974) was used. For transduction to recessive characters, cultures were incubated in L-broth containing $0.02 \mathrm{M}$-sodium citrate for $6 \mathrm{~h}$ at $37^{\circ} \mathrm{C}$ before plating on to selective medium.

Mating techniques. Hfr strains were purified by replica-mating with strain 22C53R before use. Selective plates were prepared to allow selection of recombinants which had received an early marker from Hfr strains. Rifampicin $\left(100 \mu \mathrm{g} \mathrm{ml}^{-1}\right)$ was used to counterselect against donors. For time of entry mapping, Hfr donors were grown without aeration in L-broth to $2 \times 10^{8}$ bacteria $\mathrm{ml}^{-1} . \mathrm{F}^{-}$phenocopy recipients were prepared by vigorous aeration of L-broth cultures until they had been in stationary phase for at least $12 \mathrm{~h}$. Donor and recipient bacteria were mixed in a ratio of $1: 20$ and gently aerated at $37^{\circ} \mathrm{C}$ for $60 \mathrm{~min}$. Samples were removed at intervals, diluted 10 -fold, shaken violently for $30 \mathrm{~s}$ and plated on to selective medium. Recombinants were scored after $2 \mathrm{~d}$ at $37^{\circ} \mathrm{C}$. Counterselection against donors was performed with streptomycin $\left(1 \mathrm{mg} \mathrm{ml}^{-1}\right)$. Control plates showed that the frequencies of recipient reversion, spontaneous mutation of donors to streptomycin resistance and mating pair survival after interruption were negligible. For construction of strains by conjugation, the ratio of donor to recipient bacteria was increased to $1: 2$ and the time of incubation was made appropriate to each cross.

Construction of recombination-deficient strains. To construct rec $A$ derivatives of $p d x \gamma$ mutants and of strain BL-12 ( $p d x \beta)$, spontaneous thy mutants were first isolated by plating overnight cultures on to $\mathrm{G} / \mathrm{S}$ plates supplemented with trimethoprim $\left(10 \mu \mathrm{g} \mathrm{ml}^{-1}\right)$ and thymine $\left(50 \mu \mathrm{g} \mathrm{ml}^{-1}\right)$ as described by Stacey \& Simson (1965). Thy ${ }^{-}$colonies were purified by replica-plating. Streptomycin-resistant colonies were then selected from these strains by plating on L-agar supplemented with streptomycin $\left(1 \mathrm{mg} \mathrm{ml}^{-1}\right)$. Representatives of these $p d x$ thyA $r p s L$ strains were mated with KL16-99 Hfr recA thi thy $A^{+}$and thymine-independent recombinants were selected on $\mathrm{G} / \mathrm{S}$ plates supplemented with pyridoxal and streptomycin. A number of these $t h y^{+}$recombinants (BL-3RS, BL-10RS etc.) were recognized as $r e c A$ by their greatly increased sensitivity to u.v. radiation.

Growth. Growth of bacteria in liquid culture was determined by measuring $A_{540 \mathrm{~nm}}^{1 \mathrm{~cm}}$ with a Pye Unicam SP500 spectrophotometer. Bacterial density was calculated by reference to a calibration curve.

Assay of vitamin B6. The total content of all forms of vitamin B6 in bacterial cultures (total vitamin B6) was estimated as described by Barton-Wright (1961) using Kloeckera apiculata NCYC 245 as the test organism. Before each assay, cultures were hydrolysed in $0.05 \mathrm{M}$-sulphuric acid for $3 \mathrm{~h}$ at $121{ }^{\circ} \mathrm{C}$ and insoluble material was removed by centrifugation. 


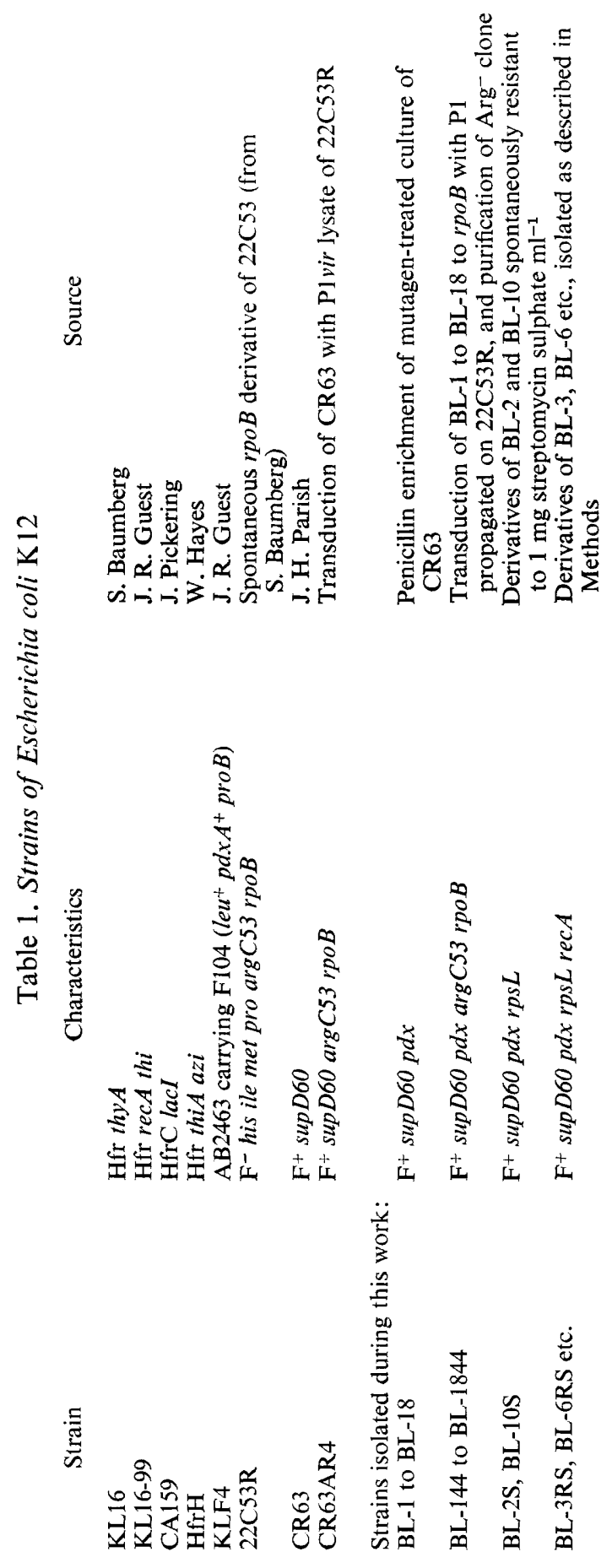




\section{Table 2. Growth requirements of vitamin B6 auxotrophs}

Washed suspensions of vitamin B6 auxotrophs were inoculated into G/S medium supplemented with $0.4 \mathrm{~mm}-2^{\prime}$-hydroxypyridoxine or with one of the B6 vitaminers at $6.0 \mu_{\mathrm{M}}$. After $48 \mathrm{~h}$ shaking $\left(17^{\circ} \mathrm{C}, 200 \mathrm{rev} . \mathrm{min}^{-1}\right)$, the growth of each culture was scored: + , growth; - , no growth.

\begin{tabular}{lcclc}
\multicolumn{1}{c}{ Strain } & $\overbrace{\text { Pyridoxine }}$ & & \\
BL-1 & Pyridoxine & $\begin{array}{c}\text { Grown with: } \\
\text { phosphate }\end{array}$ & Mutagen & Class \\
BL-2, BL-3 & - & - & U.v. & 'Oxidase' \\
BL-4, BL-5 & + & + & U.v. & 'Pre Pn' \\
BL-6 to BL-10 & - & - & U.v. & 'Oxidase' \\
BL-11 to BL-13 & + & + & U.v. & 'Pre Pn' \\
BL-14, BL-15 & + & + & EMS & 'Pre Pn' \\
BL-16 & + & - & NTG & 'Oxidase' \\
BL17, BL18 & - & + & NTG & 'Pre Pn'
\end{tabular}

All strains grew in G/S medium supplemented with pyridoxal or pyridoxal 5'-phosphate, but none grew in media supplemented with 2'-hydroxypyridoxine.

\section{RESULTS}

\section{Biochemical characterization of vitamin B6 auxotrophs}

Approximately 500 vitamin B6 auxotrophs were picked from replica plates. All auxotrophs grew in $\mathrm{G} / \mathrm{S}$ medium supplemented with one of the B6 vitaminers, but none grew in medium supplemented with $0.4 \mathrm{~mm}-2^{\prime}$-hydroxypyridoxine. The growth requirements of 18 auxotrophs which had arisen in separate mutagen-treated cultures are shown in Table 2. Two distinct classes were resolved. Mutants of one class grew only in medium supplemented with pyridoxal or pyridoxal 5'-phosphate, suggesting that they lacked pyridoxine phosphate oxidase; they were termed 'Oxidase' mutants. Mutants of the other class grew in medium supplemented with any B6 vitaminer; these were termed 'Pre Pn'. All auxotrophs, in appropriately supplemented media, grew to the same density as the wild-type parental strain in $\mathrm{G} / \mathrm{S}$ medium. The yield of auxotrophs (defined as the percentage surviving treatment with penicillin which were vitamin B6 auxotrophs) varied from $0 \cdot 2 \%$ for nitrous acid mutagenesis to $1.2 \%$ for NTG. The pyridoxal requirement of a washed suspension of one of the auxotrophs was measured in $\mathrm{G} / \mathrm{S}$ medium supplemented with pyridoxal. Both the specific growth rate and the final bacterial density were dependent on the pyridoxal concentration up to $120 \mathrm{ng} \mathrm{ml}^{-1}$. The final density attained showed a classical saturation response to increasing pyridoxal concentration.

To ensure that none of the 18 auxotrophs was a ' $\mathrm{Km}$ ' mutant, the ability of each auxotroph to synthesize vitamin B6 was investigated. Bacteria from exponentially growing cultures $\left(5 \times 10^{8}\right.$ bacteria $\left.\mathrm{ml}^{-1}\right)$ of each vitamin B6 auxotroph or of strain CR63 were removed by centrifugation and resuspended at the same concentration in $G / S$ medium. The cultures were incubated at $37^{\circ} \mathrm{C}$ for $3 \mathrm{~h}$ and samples were removed at intervals to determine the bacterial density and the total vitamin B6 concentration. The growth of CR63 and synthesis of total vitamin B6 by this strain are shown in Fig. 1(a). Two patterns of vitamin B6 synthesis were recorded for the vitamin B6 auxotrophs. Those previously classified by their growth requirement as 'Oxidase' mutants synthesized vitamin B6 at an elevated rate (Fig. $1 b$ ); this material was shown to be pyridoxine (Scott \& Hockney, 1979). None of the 'Pre Pn' mutants synthesized vitamin B6 (Fig. 1c). These results are consistent with the hypothesis that none of the vitamin B6 auxotrophs was a ' $\mathrm{Km}$ ' mutant.

Attempts to resolve the 'Pre Pn' class of vitamin B6 auxotrophs into subgroups on the basis of cross-feeding tests were unsuccessful. These tests showed that each 'Oxidase' mutant fed all 'Pre Pn' mutants very efficiently, but 'Pre Pn' mutants did not cross-feed each other. 


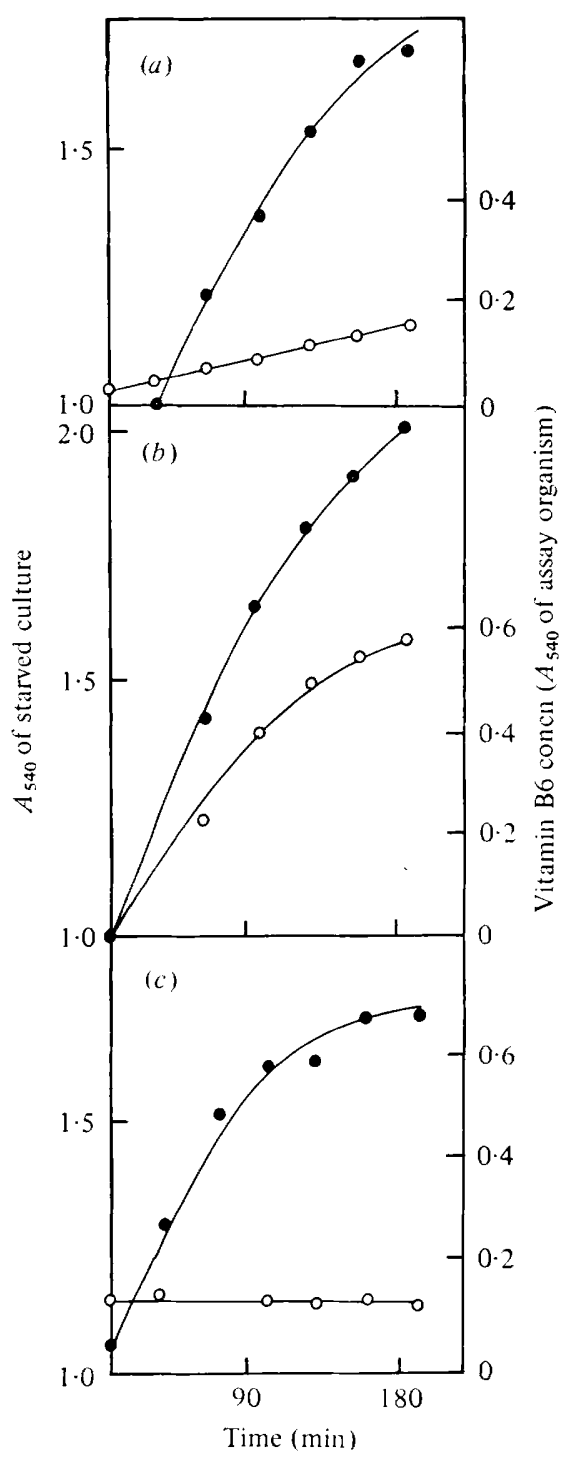

Fig. 1

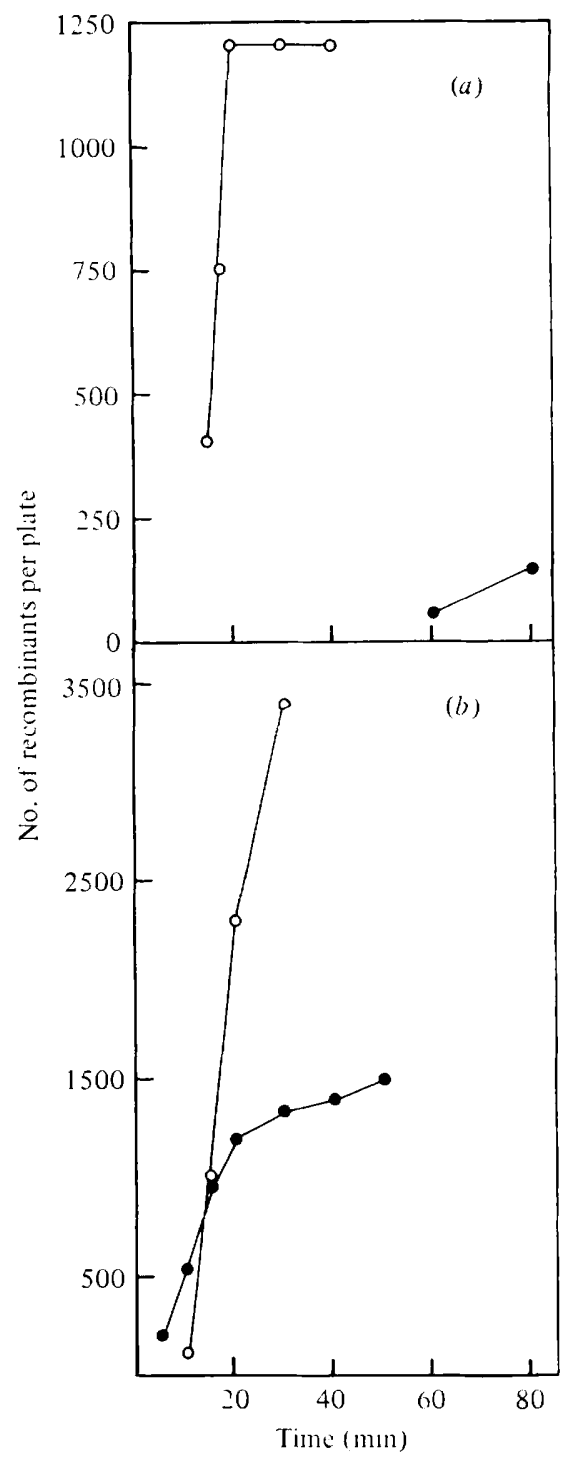

Fig. 2

Fig. 1. Time course of increase in bacterial density and total vitamin B6 concentration for vitamin B6 auxotrophs suspended in G/S medium: $O$, concentration of vitamin B6 in the culture, expressed as $A_{540}$ of the assay organism;,$A_{540}$ of starved culture. (a) Wild-type strain CR63; $(b)$ 'Oxidase' mutant BL-1; $(c)$ 'Pre Pn' mutant BL-11.

Fig. 2. Number of wild-type recombinants obtained from crosses of vitamin B6 auxotrophs with different Hfr donors, as a function of time: (a) BL-2S ( $p d x \beta) \times \mathrm{HfrH}(0)$ or KL16 (O); (b) BL-10S $(p d x \gamma) \times \mathrm{HfrH}(\bigcirc)$ or CA159, HfrC (O).

\section{Genetical characterization of vitamin B6 auxotrophs}

Transductional linkage analysis. Because the $p d x$ mutations were in a wild-type background, it was necessary to introduce a common unlinked marker into recipient strains to obtain linkage data. The $\operatorname{argC53}$ mutation was chosen as an unlinked marker because its cotransduction with $r p o B$ allowed initial positive selection of transductants. Appropriate dilutions of cultures of each vitamin B6 auxotroph transduced with a P1kc lysate of CR63AR4 were plated on L-agar supplemented with rifampicin $\left(100 \mu \mathrm{g} \mathrm{ml}^{-1}\right)$. After 


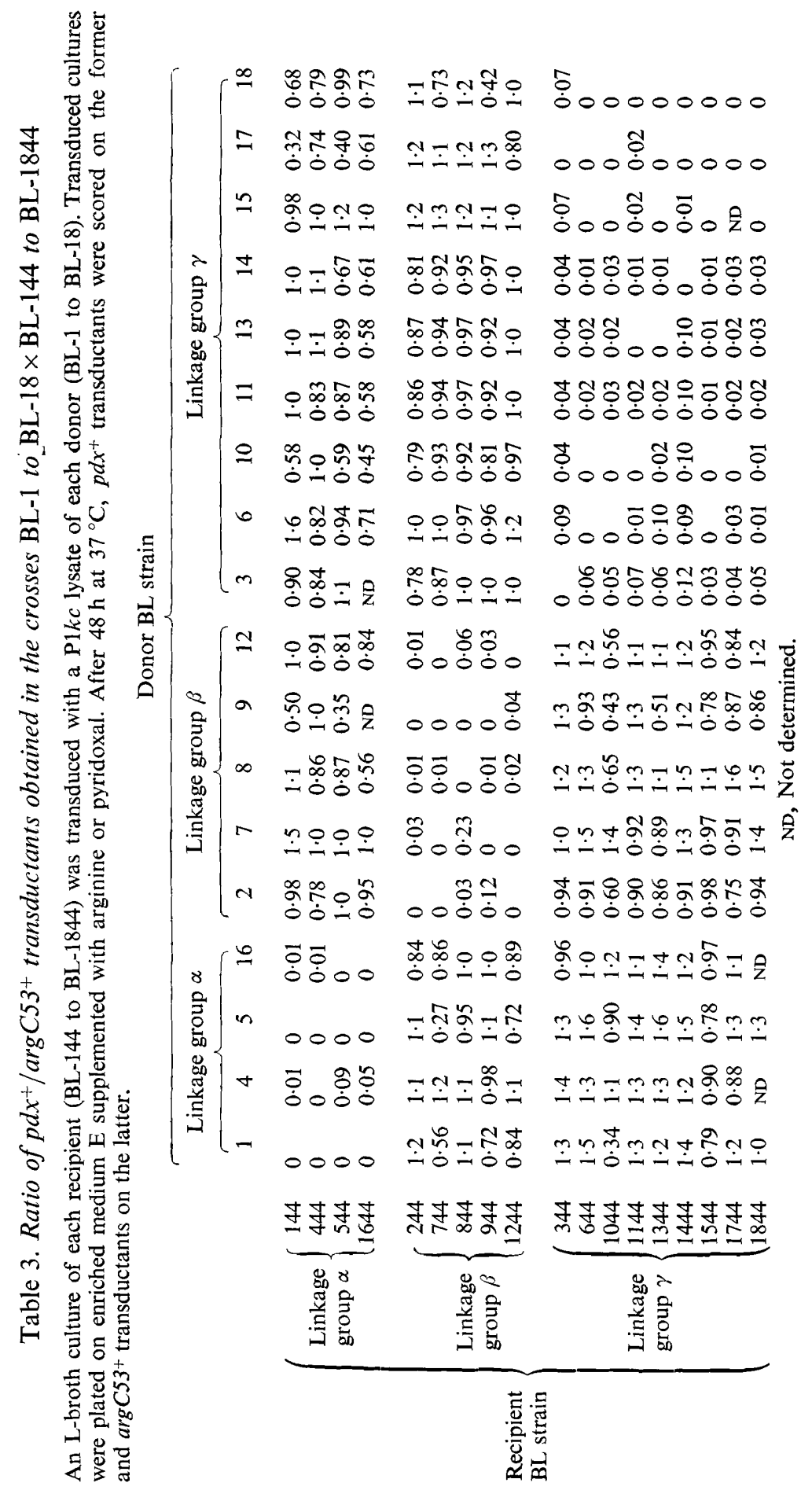


incubation these plates were used as masters for replica-plating on to $\mathrm{G} / \mathrm{S}$ plates supplemented with arginine or pyridoxal or arginine and pyridoxal. $p d x \arg C 53$ rpo $B$ transductants (BL144 to BL-1844) were picked as colonies growing only on media supplemented with both pyridoxal and arginine. No double transductants of the type $p d x^{+} \operatorname{argC53} \mathrm{rpoB}$ were found. The mean frequency of transduction to rpo $B$ was 2.9 per $10^{6}$ bacteria plated. The cotransduction frequency of $\operatorname{argC53}$ and $r p o B$ was $64 \%$. To confirm that BL-144 to BL-1844 carried $\arg C 53$ and were not arginine auxotrophs that had arisen spontaneously, an attempt was made to transduce each strain to arginine independence with a CR63AR4 lysate. Transductants were selected on enriched medium E supplemented with pyridoxal. No arginine independent transductants were observed.

To determine the linkage between $p d x$ mutations, strains BL-144 to BL-1844 were transduced with lysates of each vitamin B6 auxotroph in turn. The selective medium was enriched medium E supplemented with either arginine or pyridoxal. The ratio $p d x^{+} /$ $\operatorname{argC53^{+}}$ for each cross is shown in Table 3. The average number of transductants scored was 226. Strain BL-744 consistently gave more wild-type transductants than any other recipient. These results show that each $p d x$ mutation can be assigned to one of three linkage groups. The 'Oxidase' mutations were confined to linkage group $\alpha$. The 'Pre Pn' mutations were resolved into groups $\beta$ and $\gamma$.

Mapping of $p d x \beta$ and $p d x \gamma$. Spontaneously arising, streptomycin-resistant derivatives of auxotrophs representative of linkage groups $\beta$ and $\gamma$, designated BL-2S and BL-10S, respectively, were mated with a number of Hfr donors. From the times of entry of $p d x \beta^{+}$ from strains HfrH and KL16 into BL-2S (Fig. 2a), a map position of $48.5 \mathrm{~min}$ was calculated for this gene. Similarly, from the times of entry of $p d x \gamma^{+}$from strains $\mathrm{HfrH}$ and CA159 (HfrC) into BL-10S (Fig. $2 b$ ), a map position of 1.8 min was calculated for $p d x \gamma$.

The map position of $p d x \gamma$ suggested that this gene might be identical with $p d x A$, previously mapped at $1.0 \mathrm{~min}$ (Taylor \& Trotter, 1967). To provide further evidence in support of this suggestion, four auxotrophs carrying different $p d x \gamma$ mutations (BL-10, BL-14, BL-17 and BL-18) were mated with KLF4, an $\mathrm{F}^{\prime}$ strain carrying the F104 $l e \dot{u}^{+} p d x A^{+}$ pro $B$ plasmid. Pyridoxine-independent recombinants were selected on $\mathrm{G} / \mathrm{S}$ plates: in each case, pyridoxine-independent colonies were observed, the mean number scored being 502. $p d x y$ is thus recessive to genes carried by the F104 plasmid.

Complementation analysis of $p d x \gamma$. Abortive transductants were not observed in any cross between the nine recipient strains carrying $p d x \gamma$ recA rpsL and donor $p d x y$ strains BL-10 or BL-17. Many abortive transductants were observed in control crosses in which these strains were transduced with a lysate of strain BL-5 $(p d x \alpha)$, and in which strain BL-12RS ( $p d x \beta$ rec $A$ rps $L$ ) was transduced with lysates of strains BL-10 and BL-17. These results are consistent only with the interpretation that all $p d x \gamma$ mutations are located within the same gene.

\section{DISCUSSION}

Vitamin B6 auxotrophs of $E$. coli $\mathrm{K} 12$ clearly differ from those of $E$. coli B. Whilst all vitamin B6 auxotrophs of $E$. coli $\mathrm{K} 12$ isolated in this laboratory grew in G/S medium supplemented with pyridoxal 5 '-phosphate, only leaky auxotrophs of $E$. coli B grew when provided with this compound, the end-product of vitamin B6 biosynthesis. The two strains of $E$. coli probably differ in their ability to transport phosphorylated B6 vitaminers (see Mulligan \& Snell, 1977). Similarly whilst auxotrophs of $E$. coli K12 could be picked from replica plates after a single $2 \mathrm{~h}$ exposure to penicillin $\mathrm{G}$, the isolation of vitamin B6 auxotrophs of $E$. coli B required a minimum of three penicillin cycles (Dempsey \& Pachler, 1966). This could be due to a greater penicillin sensitivity of $E$. coli $\mathrm{K} 12$, or to a high loss of vitamin B6 auxotrophs of $E$. coli B during enrichment.

Approximately half of the 500 auxotrophs initially picked displayed the 'Oxidase' phenotype. This might suggest that the gene encoding pyridoxine phosphate oxidase is 
highly susceptible to mutation, but the more likely cause is cross-feeding during enrichment. During vitamin B6 starvation of auxotrophs prior to addition of penicillin, 'Oxidase' mutants excrete pyridoxine into the medium (Scott \& Hockney, 1979). On addition of penicillin, many 'Pre Pn' mutants will be growing on this pyridoxine and therefore subject to sterilization. 'Oxidase' mutants are not killed thus leading to an elevated yield of mutants of the 'Oxidase' type relative to the 'Pre Pn' type.

To ensure that each auxotroph isolated was defective in vitamin B6 biosynthesis rather than a ' $\mathrm{Km}$ ' mutant, a rapid and reliable screen for the ' $\mathrm{Km}$ ' phenotype was developed. This was based on the assumption that the vitamin B6 concentration of a culture of a true vitamin B6 auxotroph would remain constant or fall during vitamin B6 starvation, whereas that of a ' $\mathrm{Km}$ ' mutant would rise due to continued synthesis of the vitamin. Each auxotroph responded to this test in the manner expected of a true vitamin B6 auxotroph. The increase in bacterial density on transferring exponentially growing auxotrophs into medium lacking vitamin B6 is a general feature of coenzyme starvation (Wilson \& Pardee, 1962).

Each 'Pre Pn' mutant was defective in one of two separate linkage groups; these were designated $p d x \beta$ and $p d x \gamma$ to avoid confusion with previously identified genes in $E$. coli K12. The failure to observe cross-feeding between 'Pre Pn' strains carrying non-allelic mutations has not yet been explained. An analogous situation, however, has been reported in the synthesis of NAD by $E$. coli $\mathrm{K} 12$ (Griffith et al., 1975); each of the products of two non-allelic genes is inactive in the absence of the other, and no intermediates are excreted by mutants.

The phenotype displayed by 'Oxidase' mutants suggests that linkage group $\alpha$, to which these mutants were confined, is identical with $p d x H$, the gene mapped at 36 min in $E$. coli $\mathrm{K} 12$ and shown to determine the synthesis of pyridoxine phosphate oxidase (Bachmann et al., 1976; Shimizu \& Dempsey, 1976). The data presented concerning $p d x \beta$ and $p d x \gamma$ were taken as reasonable, but not conclusive, evidence that these genes are probably identical with $p d x B$ and $p d x A$, respectively.

The isolation of $E$. coli $\mathrm{K} 12$ auxotrophs carrying closely linked mutations in the $p d x A$ region made it possible to test whether these mutations were allelic or were located in two very closely linked genes, as suggested by the data of Dempsey $(1969 a, b)$. Complementation tests with these strains were consistent only with the interpretation that all $p d x A$ mutations are allelic. The results with $E$. coli $\mathrm{B}$ which suggested that there are two closely linked genes in the $p d x A$ region possibly arose from the mistaken assignment of two different genotypes, or even phenotypes, to interfeeding linkage group II mutants. The display of two different phenotypes by mutants defective in $p d x A$ would be possible if this gene determined the synthesis of a single polypeptide chain which catalysed two separate reactions in the biosynthesis of vitamin B6. Precedents for this are known in the euglena tryptophan pathway (Hankins \& Mills, 1977) and in the formation and interconversion of tetrahydrofolate coenzymes (Paukert et al., 1976).

We thank all who provided strains used in this work, the Science Research Council for a Studentship to R.C.H. and Mrs T. Beetham for technical help.

\section{REFERENCES}

Adelberg, E. A., Mandel, M. \& Chen, G. C. C. (1965). Optimal conditions for mutagenesis by $N$-methyl- $N^{\prime}$-nitro- $N$-nitrosoguanidine in Escherichia coli K-12. Biochemical and Biophysical Research Communications 18, 788-795.

Bachmann, B. J., Low, K. B. \& TAYlor, A. L. (1976). Recalibrated linkage map of Escherichia coli K-12. Bacteriological Reviews 40, 116-167.
Barton-Wright, E. C. (1961). Practical Methods for the Microbiological Assay of the Vitamin BComplex and Amino Acids, 1st edn, p. 27. London: United Trade Press.

BukHaRI, A. I. \& TAYloR, A. L. (1971). Mutants of Escherichia coli with a growth requirement for either lysine or pyridoxine. Journal of Bacteriology 105, 988-998. 
Davis, B. D. \& Mingioli, E. S. (1950). Mutants of Escherichia coli requiring methionine or vitamin B12. Journal of Bacteriology 60, 17-28.

DEMPSEY, W. B. $(1969 a)$. Characterization of pyridoxine auxotrophs of Escherichia coli: PI transduction. Journal of Bacteriology 97, 14031410.

DEMPSEY, W. B. $(1969 b)$. Characterization of pyridoxine auxotrophs of Eschericha coli: chromosomal position of linkage group I. Journal of Bacteriology 100, 295-300.

Dempsey, W. B. \& Pachler, P. F. (1966). Isolation and characterization of pyridoxine auxotrophs of Escherichia coli. Journal of Bacteriology 91, $642-645$

Griffith, G. R., Chandler, J. L. R. \& Gholson, R. K. (1975). Studies on the de novo biosynthesis of NAD in Escherichia coli. European Journal of Biochemistry 54, 239-245.

Guest, J. R. (1974). Gene-protein relationships of the $\alpha$-keto acid dehydrogenase complexes of Escherichia coli K-12: chromosomal location of the lipoamide dehydrogenase gene. Journal of General Microbiology 80, 523-532.

Guirard, B. M., Ames, B. N. \& SNell, E. E. (1971). Salmonella typhimurium mutants with alternative requirements for vitamin $\mathrm{B} 6$ or isoleucine. Journal of Bacteriology 108, 359-363.

Hankins, C. N. \& Mills, S. E. (1977). A dimer of a single polypeptide chain catalyzes the terminal four reactions of the L-tryptophan pathway in Euglena gracilis. Journal of Biological Chemistry 252, 235-239.

Henderson, G. B. \& Snell, E. E. (1971). Vitamin B6 responsive histidine deficiency in mutants of Salmonella typhimurium. Proceedings of the National Academy of Sciences of the United States of America 68, 2903-2907.
LenNox, E. S. (1955). Transduction of linked genetic characters of the host by bacteriophage P1. Virology 1, 190-206.

Mulligan, J. H. \& Snell, E. E. (1977). Transport and metabolism of vitamin $\mathrm{E} 6$ in lactic acid bacteria. Journal of Biological Chemistry 252, $835-839$.

Paukert, J. L., D'Ari Straus, L. \& Rabinowitz, J. C. (1976). Formylmethenyl-methylenetetrahydrofolate synthetase (combined). Journal of Biological Chemistry 251, 5104-5111.

Scott, T. A. \& Hockney, R. C. (1979). Synthesis of vitamin B6 by a mutant of Escherichia coli $\mathrm{K} 12$ and the action of $4^{\prime}$-deoxypyridoxine. Journal of General Microbiology 110, 285-289.

Scott, T. A. \& PICTON, C. (1976). The conversion of 3-hydroxy-2,4,5-trihydroxymethyl pyridine into pyridoxine by Kloeckera apiculata. Biochemical Journal 154, 35-41.

Shimizu, S. \& Dempsey, W. B. (1976). Genetic map position of the $p d x H$ gene in Escherichia coli. Journal of Bacteriology 127, 1593-1594.

Stacey, K. A. \& Simson, E. (1965). Improved method for the isolation of thymine-requiring mutants of Escherichia coli. Journal of Bacteriology 90, 554-555.

TAylor, A. L. \& Trotter, C. D. (1967). Revised linkage map of Escherichia coli. Bacteriological Reviews 31, 332-353.

Torriani, A. \& Rothman, F. (1961). Mutants of Escherichia coli constitutive for alkaline phosphatase. Journal of Bacteriology 81, 835-836.

VOGEL, H. \& BONNER, D. M. (1956). A convenient growth medium for Escherichia coli and some other microorganisms. Microbial Genetics Bulletin 13, 43-44.

Wilson, A. C. \& PARdeE, A. B. (1962). Regulation of flavin synthesis by Escherichia coli. Journal of General Microbiology 28, 283-303. 